\title{
Raça, classe e cultura no contexto das políticas de ação afirmativa: um esforço teórico- crítico a respeito da raça
}

\author{
Lília Gonçalves Magalhães Tavolaro \\ Ph.D. em Sociologia (The New School for Social Research/Nova York) \\ Professora da Universidade Federal de Uberlândia \\ Uberlândia, Brasil \\ liliatavolaro@hotmail.com
}

\begin{abstract}
Resumo O presente artigo se propõe a discutir três questões caras ao debate sociológico em torno das chamadas "questões raciais" e, de algum modo, retomadas no contexto da implementação das políticas de cotas no Brasil, a saber: a relação entre raça e classe; a interface da raça com a cultura/etnia; e o status da raça como categoria social e conceito analítico. Esta discussão será feita à luz do debate que antecedeu e se intensificou por ocasião da introdução das primeiras políticas de cotas em universidades públicas. Primeiramente, faz-se uma incursão em torno do embate teórico relativo à interdependência das categorias "raça" e "classe" de modo a exemplificar a maneira através da qual elas se relacionam no contexto da experiência de ações afirmativas para negros. Em seguida, desenvolve-se uma reflexão crítica a respeito da interface teórica entre raça e cultura à luz das disputas relativas aos significados da identidade negra nesse contexto. Finalmente, analisam-se as discussões em torno dos significados raciais no contexto da implementação de políticas públicas afirmativas, com o objetivo de propor uma análise reflexiva a respeito da raça como conceito analítico.
\end{abstract}

Palavras-chave: raça, racismo, classe social, etnicidade, ações afirmativas.

$\mathrm{P}$ ara muitos, a introdução de políticas raciais afirmativas constituía um projeto inalcançável ou pelo menos muito remoto num país no qual todos pareciam estar ainda "intoxicados" pelo mito da democracia racial. De fato, foi somente a partir dos eventos preparatórios para a participação brasileira na III Conferência Mundial contra o Racismo, Discriminação Racial, Xenofobia e Intolerância Correlata ocorrida em Durban, em 2001, que as primeiras iniciativas no âmbito da política institucional foram efetivamente tomadas. Nesse sentido, destacaram-se as políticas de cotas para negros em universidades públicas brasileiras, as quais geraram acalorados debates não só no meio acadêmico, mas também entre outros formadores de opinião pública na mídia eletrônica e impressa.

O presente artigo propõe como tarefa discutir três questões caras ao debate sociológico em torno das chamadas "questões raciais" - de algum modo, retomadas no contexto das políticas de cotas nas universidades públicas -, a saber: 1) a relação entre raça e classe; 2) a interface da raça com a cultura/etnia; e 3) o status da raça como categoria social e conceito analítico. Para tanto, far-se-á uso de dados coletados (por meio de entrevistas, matérias de jornais e textos acadêmicos) para minha tese de doutorado a respeito do processo de resignificação de categorias raciais no contexto das cotas na UERJ e UnB (Tavolaro, 2006). 
Com relação ao primeiro aspecto, é possível dizer que, de um modo geral, as políticas raciais afirmativas recentemente implementadas no Brasil se pautam em abordagens da questão racial que enfatizam a necessidade de tratar a raça como fenômeno social com uma dinâmica própria e não como mero epifenômeno da estrutura de classes. Essa forma de conceber a raça encontra suporte numa literatura relativamente recente no campo das ciências sociais, que aponta para as especificidades do fenômeno social da raça em relação à classe e reivindica a autonomia da raça como conceito analítico.

De fato, ao fazer uma distinção analítica entre classe e status como fenômenos de poder pertencentes a diferentes ordens de estratificação, Weber (1982) já havia indicado que, em vez de um "efeito colateral" do poder economicamente determinado, a raça constitui um fenômeno social mais especificamente relacionado à honraria de status que, neste caso, baseia-se numa distinção hierárquica fundamentada em características físicas.

Contudo, a maioria das abordagens sociológicas contemporâneas que lidam com a raça como variável independente refuta aquelas teorias da modernidade, segundo as quais a classificação racial tenderia a desaparecer como modo de estratificação social significativo uma vez que as relações sociais capitalistas viriam substituir aquelas predominantes em sociedades pré-modernas. Tais abordagens constituem também uma resposta àquelas interpretações que veem o racismo como mera manobra ideológica das sociedades capitalistas para manter o status quo. ${ }^{1}$

Em sua análise a respeito do que chamam "formação racial" nos Estados Unidos, por exemplo, Omi e Winant (1994) refutam as abordagens "economicistas" do racismo e criticam, em especial, a tese de William Wilson (1980) sobre o declínio da importância da raça na determinação das desigualdades sociais. Wilson argumenta que, desde 1965, é possível observar um declínio na influência da raça sobre a determinação das oportunidades de vida para os negros americanos. Segundo Wilson, a estrutura de classe tornou-se, a partir da segunda metade do século XX, mais determinante no acesso dos negros ao privilégio e ao poder. Com isso, Wilson não quer dizer que não haja mais conflito racial. Mas, de acordo com ele, enquanto a opressão racialmente motivada do passado excluía toda a população de negros, atualmente as barreiras do racismo se erguem principalmente em torno dos negros pobres, o que constitui uma indicação de que "elas são raciais apenas em suas consequên- cias e não em suas origens" (Wilson, 1980, p. 2). Para Omi e Winant, pelo contrário, a persistência do racismo nas sociedades capitalistas contemporâneas se deve à permanência contínua da raça como princípio estruturante da estratificação social e da organização da cultura e da política.

Argumento semelhante foi desenvolvido por Carlos Hasenbalg (1979) em sua pesquisa a respeito da persistência da ordem racista na sociedade brasileira capitalista. Para Hasenbalg, a pouca mobilidade social entre os negros e o fato de permanecerem ocupando uma posição subordinada na estrutura de classe e estratificação social brasileiras constituía uma evidência de que eles estavam sujeitos a "uma desqualificação peculiar e a desvantagens competitivas que derivavam de sua condição racial" (Hasenbalg, 1979, p. 20). Segundo esse autor, o mito da democracia racial teve os seguintes desdobramentos: fez com que as questões raciais fossem tratadas como questões de desigualdade de classe e, consequentemente, levou à invisibilidade da raça através de "formas sutis de manipulação ideológica que tendiam a esconder a divisão racial através da ênfase nas formas simbólicas de integração" (Hasenbalg, 1979, p. 225).

De fato, a raça continua sendo significante e consequente como categoria de classificação social nas sociedades capitalistas contemporâneas. Fato é que as pessoas continuam sendo discriminadas com base na significação negativa de suas características fenotípicas e o conflito social nas sociedades modernas é, em alguns casos, crescentemente baseado na crença de que pessoas de "origens diferentes" são naturalmente incompatíveis. Conforme observou Hasenbalg (1979), no Brasil, o intenso desenvolvimento econômico ocorrido entre a década de 1950 e meados da década de 1970 certamente não resultou numa sociedade menos racista. Além de serem frequentes nas relações intersubjetivas cotidianas, as manifestações de racismo, neste país, têm sido amplamente reportadas, especialmente nas duas últimas décadas, através da mídia impressa e eletrônica, bem como registradas nas pesquisas acadêmicas.

Isso também é verdade para os chamados "países centrais" do sistema capitalista mundial. $\mathrm{Na} \mathrm{Eu-}$ ropa Ocidental, por exemplo, a unificação política e a construção de uma cidadania supranacional foram acompanhadas por demonstrações perturbadoras de intolerância que parecem reproduzir a ordem racista. ${ }^{2}$ Nos Estados Unidos, o conflito social é frequentemente causado e agravado por concepções raci(ali)stas do outro, vide os levantes de Los Angeles em 1992.

1. A interpretação do racismo como ideologia das sociedades capitalistas pode ser encontrada, por exemplo, nas considerações de Balibar e Wallerstein (1990) a respeito da emergência de manifestações racistas na Europa contemporânea.

2. Para uma consideração de novas manifestações de racismo na sociedade Européia contemporânea ver: Balibar (1991), Stolcke (1993) e Fekete e Webber (1994). 
O racismo é, ademais, um fenômeno registrado por estudos recentes acerca da posição desvantajosa de estudantes negros na disputa por uma vaga nas universidades públicas. Uma pesquisa a respeito do desempenho dos estudantes negros no vestibular da Universidade de São Paulo, por exemplo, mostra que, além de problemas estruturais, eles enfrentam constrangimentos "subjetivos" - tais como a baixa autoestima resultante de experiências constantes de discriminação racial - na disputa por uma vaga naquela que é considerada a universidade mais prestigiosa do país (Guimarães, 2003).

Há, contudo, evidências de que um completo destacamento da raça em relação à classe pode ser enganoso, especialmente se se considerarem os modos significativos pelos quais a classe social - entendida também em sua dimensão simbólica mais do que propriamente econômica - interage com a significação racial. Eu me refiro aqui mais especificamente àquele conjunto de características comumente associadas ou atribuídas às pessoas pertencentes a uma determinada situação de classe ou posição na estratificação socioeconômica e sua estreita interconexão com a identificação racial. ${ }^{3}$

Isso se evidencia no caso da implementação de cotas na Universidade do Estado do Rio de Janeiro (UERJ), onde os legisladores falaram indistintamente de negros e pobres ao justificarem a necessidade de aprovar a política de ação afirmativa. De fato, ao se analisarem os discursos dos deputados na Assembleia Legislativa do Estado do Rio de Janeiro, por ocasião da votação da política de cotas nas universidades estaduais, não é difícil ver o modo como as categorias de raça e classe estiveram intimamente entrelaçadas naquele contexto. Conforme já observado por Peter Fry, no debate que precedeu a sessão de votação do Projeto de Lei n. 503/2003 (que propunha uma nova lei de cotas nas universidades estaduais fluminenses), ${ }^{4}$ os discursos se centraram na questão da desigualdade social a tal ponto que, por vezes, "negro" tornou-se sinônimo de "pobre" (Fry, 2005, p. 329). A deputada estadual e ativista negra Jurema Batista, por exemplo, argumentou que, após a abolição, os negros se viram "aprisionados pela miséria das favelas", sendo esta a razão pela qual hoje se viam impedidos de competir em igualdade de condições com os "descendentes dos donos de escravos". Estes, segundo ela, "construíram sua riqueza à custa do sangue do povo negro" (Batista apud Rio de Janeiro, 2003, p. 31). Para a deputada, a inclusão dos negros na universidade implicaria a construção de um universo acadêmico mais diverso na medida em que esta incorporaria a "perspectiva dos excluídos" - nesse caso, claramente identificada com a perspectiva dos pobres, habitantes das favelas no conhecimento científico.

Da mesma forma, os estudantes da UERJ beneficiados com as "cotas raciais" elaboraram um discurso de diversidade cultural que contemplava a situação de classe. De fato, em um contexto em que a categoria "carente" acabou se tornando determinante na política de cotas, a perspectiva "étnica" da raça - que identifica a "raça negra" com determinados valores e tradições culturais - misturou-se com uma definição de negritude que incluía a condição dos negros de excluídos socioeconomicamente e de habitantes majoritários das favelas do Rio de Janeiro (Tavolaro, 2008).

Para uma estudante negra e cotista do curso de Graduação em Geografia da UERJ, por exemplo, a situação de desvantagem socioeconômica constitui um critério válido para definir os beneficiários das cotas para negros já que consiste em uma característica determinante fundamental da condição da população negra e em uma maneira de contornar os constrangimentos da definição arbitrária dos "verdadeiros negros":

Bom, eu entrei na primeira turma onde não tinha esse recorte de renda, então todo e qualquer negro ou pardo entravam e muitos de má fé se declaravam pardos e entravam pra Direito, Medicina, esses cursos que tem um status maior. Conheço um que entrou comigo [...], ele tem acho que 22; entrou pelas cotas. Pra mim, ele é negro, mas ele não se acha. Assim, ele não tem essa identidade racial de pensar que o racismo, enfim essa série de coisas... Aí, ele me disse que era contra as cotas e fez prova de novo em 2003 pra Direito e entrou pelas cotas. Ainda não tinha esse recorte [de renda]. [...] Eu acho que o recorte de renda é bom porque entram pessoas que realmente precisam né? Eu acho que tem que ter a foto também, mas, assim, quem é que vai julgar quem é negro ou não? É complicado também... (Estudante de graduação da

3. Stuart Hall (1996) utiliza o termo "identificação" para enfatizar a natureza discursiva, contingente, histórica, mutável e múltipla dos processos de formação de identidade em contraposição à dimensão essencialista, fixa, e unificada embutida na ideia de identidade.

4. As cotas para negros foram primeiramente implementadas nas universidades estaduais fluminenses em 2002, através da Lei n. 3.708/2001. Essa lei complementava outra, de autoria do então governador do estado do Rio de Janeiro, Anthony Garotinho, Lei n. 3.524/2000, que obrigava as universidades estaduais a reservar $50 \%$ de suas vagas para estudantes egressos de escolas de escoas públicas. Após ter sofrido cerca de 300 processos judiciários questionando os termos das leis de cotas, o estado do Rio de Janeiro reformulou a política de cotas através de uma nova lei sancionada em 2003 (Lei n. 4.151/2003), que reservava 45\% das vagas das universidades estaduais do Rio de Janeiro para estudantes "carentes", dentre as quais 20\% deveriam se destinar aos estudantes egressos de escolas públicas, $20 \%$ aos negros e $5 \%$ às pessoas com necessidades especiais e às minorias étnicas. 
UERJ, entrevista concedida na UERJ, no Rio de Janeiro em 4/5/2006)

A correlação entre a identidade negra e a posição desvantajosa na estrutura de classes também ficou evidente no seguinte depoimento de uma estudante negra pós-graduanda em Letras da UERJ e ex-membro do Coletivo Estadual de Negros Universitários (CENUN):

Pra mim, a negritude é um lugar, o lugar onde as pessoas estão; o lugar que as pessoas ocupam; um lugar social mesmo; um lugar marcado pelas privações. Então, cada vez mais, mesmo que eu nunca deixe de me considerar negra, cada vez mais eu me afasto do imaginário do que é ser um negro. Porque ser um negro, pela visão histórica, por aquilo que você espera historicamente, é uma pessoa desprovida de muitas coisas. E eu não posso mais me considerar desprovida [...]. O meu caminho, ainda bem, foi traçado, tá ótimo, tá lindo... Eu tenho espaço, eu trabalho aqui dentro da UERJ, eu tenho vaga, eu tenho meu carro, eu tenho minha vida. Mas eu entendo que as pessoas ainda não têm e que é preciso lutar por isso também. (Estudante de pós-graduação da UERJ, entrevista concedida na UERJ, no Rio de Janeiro em 4/7/2005)

É interessante notar como a relação entre raça e classe se fez relevante num contexto em que as cotas raciais foram concebidas como política de redistribuição, enquanto a dificuldade de acesso dos negros à universidade pública era entendida como algo que decorria primordialmente de sua posição socioeconômica desvantajosa. Nesse sentido, mais do que a expressão da subordinação axiomática da raça em relação à situação de classe, ou, do contrário, de que ambas as categorias devem ser concebidas como variáveis independentes uma da outra, o caso da UERJ indica que a relação entre a identificação racial e a situação de classe deve ser entendida como algo dado em circunstâncias e contextos históricos e institucionais específicos.

Outra questão controversa levantada pelo atual debate a respeito das políticas de cotas no Brasil diz respeito à interface entre raça e cultura. Os defensores desse tipo de ação afirmativa argumentam, com frequência, que tais medidas compensatórias são imprescindíveis à construção de uma sociedade verdadeiramente multicultural e plural. Essa perspectiva sugere que, muito além da aparência física, a identidade negra implica principalmente a identificação com a cultura e tradições "negras" ou de origem africana. A ideia aqui é de que a inclusão dos negros na universidade pública não irá apenas compensar a desigualdade histórica entre negros e brancos, dando aos primeiros uma oportunidade de ascensão social. Mais do que isso, a política de cotas é concebida como uma oportunidade de os negros contribuírem para o ambiente acadêmico com novas concepções de mundo dadas não só por sua condição de excluídos, mas por suas "raízes culturais africanas". Isso se evidencia, por exemplo, em Uma proposta de cotas para estudantes negros na Universidade de Brasília, de José Jorge de Carvalho e Rita Segato. Nesse documento - que orientou posteriormente o "Plano de metas para a integração social, étnica e racial da Universidade de Brasília", aprovado pelo Conselho de Ensino, Pesquisa e Extensão da UnB em junho de 2003 -, Carvalho e Segato argumentaram que a admissão de negros na universidade contribuiria necessariamente para tornar o ambiente acadêmico mais diverso e plural, já que até então prevaleciam nesse meio as perspectivas eurocêntricas e ocidentais do mundo. Ao se referirem aos resultados esperados da política de cotas para negros na UnB, esses autores afirmam:

Essa mudança de critérios de acesso à universidade, além do evidente impacto no imaginário de nossa sociedade, provocará também um impacto de dimensões consideráveis sobre o conhecimento reproduzido e gerado na UnB. A presença, nas salas de aula, de um número mínimo de estudantes negros (e a médio prazo, esperamos, também de professores negros) oferecerá uma excelente oportunidade para se revisar e ampliar as teorias e os conteúdos quase que exclusivamente ocidentalizantes e eurocêntricos que são passados em inúmeras disciplinas da universidade. Será dada à UnB uma oportunidade de ser mais uma vez vanguarda na abertura de novos temas de estudos e de uma ampliação das abordagens preestabelecidas. [...] A experiência negra impregnará intelectualmente disciplinas diversas dos cursos de História, Letras, Linguística, Geografia, Serviço Social, Antropologia, Sociologia, Comunicação, Artes Visuais, Artes Cênicas, Música, Filosofia, Psicologia, Saúde Pública, entre tantas outras. Ou seja, junto com a presença física dos negros entrará também um olhar não-branco sobre inúmeras dimensões do conhecimento humano que reproduzimos na UnB sob uma ótica predominantemente européia. Novas especializações, áreas de pesquisa, disciplinas e até cursos de pós-graduação haverão de surgir como resultado dessa nova convivência inter-racial. (Carvalho; Segato, 2002, p. 31-32)

É certo que a categorização social baseada na significação de características biológicas (sejam elas aparentes ou imaginadas) como marca da diferença e mecanismo de opressão levou à formação de grupos que compartilham uma identidade negra com base na crença em uma origem, língua, religião e "estoque cultural" comuns. No entanto, conceber uma determinada identidade étnica como resultante inevitável 
ou automática da categorização racial pode levar a graves desentendimentos cognitivos e morais. Eu me refiro, aqui, especificamente aos riscos de associar diretamente sujeitos racialmente significados a um mesmo background cultural, a uma filiação política ou religiosa, ou a um comportamento social específico. Essa operação, no meu modo de entender, parece não escapar ao caráter essencialista da ordem racista prevalecente.

De fato, a interconexão entre raça e etnia como categorias sociais e critérios de classificação simbólica constitui uma questão polêmica entre os pesquisadores dedicados ao estudo das identidades coletivas e formação de grupos, em razão, principalmente, da falta de consenso com seus significados enquanto conceitos analíticos. ${ }^{5}$ Os cientistas sociais que têm analisado essas questões do ponto de vista da perspectiva do Cultural Studies, por exemplo, propõem a substituição do termo "raça" por "etnia", para salientar o lugar da história, da cultura e da política no processo de construção de identidades coletivas. Neste caso, o termo "etnia", ou "etnicidade", é analiticamente empregado para evitar o essencialismo contido no termo "raça", tal como usado na linguagem comum (Cornell; Hartmann, 1998). De fato, conforme argumentarei adiante, se quisermos entender e explicar a complexa dinâmica da categorização racial e suas consequências sociais sem reproduzir a "visão e divisão" ordinária - e racista - do mundo, devemos nos livrar da raça como categoria analítica, bem como de um tipo de interpretação centrada nos "grupos raciais" como ponto de partida da pesquisa. $\mathrm{E}$, em vez disso, devemos falar do processo histórico e social através dos quais a raça veio a constituir-se como uma poderosa categoria de classificação social. De qualquer modo, para melhor compreender raça como fenômeno social, em vez de usar etnia como sinônimo de raça, devemos lidar com o fenômeno social da raça como resultado de um modo específico de significação social, a saber: o racismo, pois, embora indivíduos racialmente categorizados possam realmente construir um senso compartilhado de etnicidade, eles não o farão necessariamente.

Isso não quer dizer que devemos desprezar a relevância social da "negritude" como fenômeno político e cultural e como fonte de solidariedade social entre aqueles que vêm sendo historicamente discriminados em razão da significação negativa da cor de sua pele ou de seu fenótipo. Tanto quanto em outros países marcados com as cicatrizes da escravidão, no Brasil, a opressão histórica de descendentes dos vários povos africanos que aqui viveram e sua transformação em uma única "raça negra" foi seguida de uma reinvenção da África como lugar de origem e referência cultural para a construção de uma identidade coletiva. ${ }^{6}$ Entretanto, assim como a racialização dos nativos da África e seus descendentes deve ser vista como resultado de um processo social e político de dominação e opressão e não como fenômeno inexorável supostamente dado por diferenças físicas objetivas, a etnicização dos negros deve ser analisada à luz das circunstâncias particulares que a tornam mais ou menos "favorável", ou mais ou menos "relevante" como critério de identidade coletiva.

De fato, embora a sociedade brasileira experimente atualmente um processo crescente de afirmação da negritude, há muita disputa em torno daqueles elementos constituintes de uma "autêntica" cultura negra. Isso aparece, novamente, de forma particularmente evidente no processo de implementação de cotas nas universidades públicas brasileiras, onde o discurso em prol da valorização e visibilidade da cultura negra vem acompanhado de disputas em torno dos seus significados e onde um senso de identidade étnica negra é, muitas vezes, contestado como critério legítimo de definição dos beneficiários das cotas. Alguns formuladores das políticas de cotas argumentam, por exemplo, que a identificação com uma cultura negra ainda não constitui, no Brasil, um aspecto suficientemente consolidado da identidade negra entre aqueles que sofrem discriminação e preconceito em razão da significação negativa de sua cor.

Ao considerar, por exemplo, o caráter fragmentado dos movimentos negros no Brasil, Burdick (1998) afirma que o enfoque dos movimentos negros na religiosidade africana, como base legítima para uma identidade negra autêntica - em oposição às religiões cristãs que, são, nesse caso, consideradas "alienantes" -, acaba por afugentar uma parcela considerável de militantes em potencial que, embora se percebam como vítimas de discriminação racial, são católicos ou protestantes. De acordo com Burdick (1998, p. 147-148),

vários militantes desconfiam da Igreja Católica por ter colaborado com a escravidão e ter agido como agente da Europeização. Eles também se sentem incertos quanto às devoções católicas populares aos santos que eles veem como veículos e alienação. [...] Se eles são ambivalentes com relação ao catolicismo, são radicalmente hostis ao protestantismo, especialmente ao pentecostalismo. Essas tradições religiosas são vistas por eles como forças poderosas de 'branqueamento': o negro que se converte ao protestantismo

5. Conforme já salientado por Richard Jenkins (2001, p. 74), "a relação entre 'raça' e etnicidade é algo sobre o qual há pouco consenso e uma boa dose de polêmica".

6. Para uma análise das "reinvenções da África" como lugar de origem comum entre os descendentes de Africanos no Brasil, ver Pinho (2004). 
esquece sua verdadeira identidade, rendendo-se à religião branca europeia. [...] Não deveria, portanto, surpreender que os negros que tem pouco interesse pela religiosidade africana ou que são fortemente comprometidos com o cristianismo, sintam-se pouco à vontade ou não se sintam bem-vindos entre os ativistas negros. (Tradução minha)

A experiência dos Espaços Afirmados na UERJ parece especialmente ilustrativa no que diz respeito ao caráter situacional e processual da identificação com uma cultura negra ou afro-brasileira. A dimensão "pedagógica" das atividades desenvolvidas pelo programa, tal como demonstram alguns de seus participantes que disseram estar "aprendendo a ser negros", constitui uma evidência de que a identificação com a cultura negra não consiste num efeito inevitável da categorização racial (Pinto, 2004). Enquanto os beneficiários das cotas raciais consideravam-se vítimas de discriminação racial, sua referência à identificação com a cultura negra - como processo de aprendizagem - indicava que a sua experiência de discriminação racial não teria automaticamente se seguido de um senso compartilhado de identidade cultural negra. Ao contrário, isso teria sido algo cultivado num contexto onde a construção de um senso de identidade étnica negra constituiria um fator imprescindível para os propósitos de mobilização política.

Além disso, conforme sugerido por um dos membros da comissão designada pela Universidade de Brasília para definir os beneficiários das cotas raciais, a resistência em tomar somente a identificação com a cultura afrodescendente como critério de elegibilidade resultou da noção de que, para beneficiar as "verdadeiras vítimas" do racismo, a política de cotas deveria se centrar na experiência de discriminação baseada na cor e na aparência física. Nesse caso, portanto, ficou claro que a experiência de discriminação com base na cor ou na aparência física foi percebida como algo que não necessariamente conduziria a uma identificação com uma identidade afro-brasileira. $\mathrm{Na}$ verdade, este constituiu um dos pontos de discordância entre os formuladores da política de cotas na $U n B$, que revelou visões divergentes a respeito dos significados da negritude. Carvalho e Segato (2002) sugeriram inicialmente o termo "negro" para se referir aos beneficiários das cotas raciais de modo a encorajar um senso de etnicidade negra entre as vítimas de discriminação. Outros, mais especificamente os membros da comissão de regulamentação do Plano de Metas, se valeram da ideia de que, no Brasil, as pessoas sofrem discriminação com base na sua aparência, para se centrarem na primazia do "fenótipo negro" ao definir os candidatos às cotas para negros (Tavolaro, 2006).

Finalmente, o atual debate a respeito das cotas para negros no Brasil pauta-se em discussões sobre a existência ou não da "raça" como critério legítimo de classificação dos grupos sociais. É muito comum ouvir daqueles que se opõem às cotas raciais que o conceito biológico de raça - no qual se baseiam as sociedades racistas modernas - já caiu em descrédito e que insistir na categorização racial das pessoas é não só moralmente condenável, mas cientificamente infundado. No entanto, aqueles que veem na racialização a única solução para a desigualdade racial argumentam, com frequência, que, embora a biologia tenha refutado a raça como conceito científico, esta continua sendo efetiva e tendo consequências para a vida das pessoas enquanto "categoria nativa".

Vista sob esse prisma, a raça existe como critério persistente de exclusão e não pode, portanto, ser desconsiderada na construção de uma sociedade democrática. Esta também constitui uma das questões mais polêmicas entre os cientistas sociais preocupados em explicar e compreender a raça como fenômeno social. Enquanto alguns argumentam que a raça deve ser descartada como categoria analítica com o objetivo de evitar a reprodução da visão racista da sociedade (Miles, 2000; Fields, 2003; Gilroy, 2001; Azevedo, 2004), outros argumentam que, ao fazê-lo, a pesquisa social corre o risco de desconsiderar um fenômeno social relevante e, dessa forma, apenas contribuir para agravar a manutenção do status quo. ${ }^{7} \mathrm{Na}$ verdade, tanto os "opositores" quanto os "defensores" da raça a tomam, nesse caso, como realidade social e não biológica. No entanto, uma consideração mais aprofundada a respeito da força explicativa da raça como conceito analítico, assim como as consequências de seus usos na fomentação ou impedimento da justiça social, requer uma incursão cuidadosa a respeito de que tipo de realidade social constitui a raça.

Os cientistas sociais preocupados com o impacto negativo da rejeição ao conceito de raça argumentam, de forma persuasiva, que o fato desta constituir uma construção social não a torna menos real e efetiva na vida social. Ao refletir a respeito do status teórico do conceito de raça, Howard Winant (2000) menciona, por exemplo, a noção durkheimiana de "fato social" para salientar a importância persistente da raça em contraposição àquelas abordagens que tendem a lidar com essa forma de categorização social como "mera

7. Um documento elaborado pela American Sociological Association (2003), reafirmando a importância de coletar dados e realizar pesquisa científica social sobre a raça, consiste em um bom exemplo desse ponto de vista. O documento argumenta que "as estatísticas que permitem a comparação de diferenças entre grupos étnicos e raciais nos censos, questionários públicos e base de dados administrativos" (p. 3) são cruciais para informar os formuladores de políticas públicas preocupadas em assegurar a justiça social e a igualdade de condições. 
ilusão". Segundo Winant, a efetividade da raça na organização da vida social se faz sentir pelo seu caráter duradouro (ainda que mutante) e coercitivo; ou seja, pelo fato de que ela continua sendo uma forma significativa de categorização social imposta aos indivíduos, independentemente de suas próprias concepções a respeito de si mesmos:

A longevidade do conceito de raça e a enorme gama de efeitos que o pensamento e o agir racial têm produzido garantem que a raça permanecerá como característica da realidade social através do globo e, a fortiori, nos Estados Unidos, apesar de sua falta de mérito científico (no sentido biológico). Em segundo lugar [...], no nível da experiência da vida cotidiana, a raça constitui uma parte relativamente impermeável de nossas identidades. A sociedade norte-americana é tão racializada que não ter uma identidade racial é perigar não ter identidade alguma. Não ter raça é o mesmo que não ter gênero. De fato, quando não se pode identificar a raça de alguém, ocorre uma crise de interpretação microssociológica, algo talvez mais bem interpretado em termos etno-metodológicos ou goffmanianos. (Winant, 2000, p. 184)

No meu modo de entender, o mérito da sociologia de Durkheim para compreender o status social da raça repousa no papel fundamental que ele atribui aos sistemas de crenças como sendo dados socialmente constitutivos da realidade social. Essa abordagem nos possibilita entender e explicar porque, ainda que seja o resultado de uma "operação mental coletiva" e de uma concepção específica (racista) da organização social, a raça é uma ideia, uma noção socialmente construída com consequências reais e efetivas na vida social.

Enquanto tal é certo também que não se pode desprezar sua dimensão objetiva e coercitiva na vida social. Ao enfocar sua dimensão objetiva, é preciso, no entanto, que não se percam de vista as condições históricas, políticas e sociais que a tornam possível como critério socialmente relevante de categorização. Seus significados são, ademais, questionáveis e suscetíveis às disputas em torno do poder de definição das representações hegemônicas do mundo social. $\mathrm{Na}$ verdade, uma abordagem por demais objetivista do fenômeno social da raça corre o risco de referendar a operação reificadora típica das concepções de mundo ordinárias - e racistas - que faz com que a divisão das pessoas em raças diferentes e desiguais faça parecer algo naturalmente dado. E raça é precisamente isso: uma realidade construída e reificada que se nos apresenta como se funcionasse independentemente das nossas ações de discriminação e categorização racial; algo que antecede a significação social e pertence, portanto, à "ordem natural das coisas".

Desse modo, as disputas em torno dos critérios para definir os beneficiários das cotas raciais nas universidades públicas indicam que mais do que um "fato social" inerentemente estável, consensual e inquestionável, a raça consiste numa categoria cujos significados são passíveis de disputa. É interessante notar, por exemplo, como a falta de consenso em torno dos significados da identidade negra no contexto da política de cotas não só revelou a falta de um discurso institucionalizado e amplamente compartilhado capaz de proporcionar contornos mais conspícuos e objetivos à raça, ${ }^{8}$ como foi potencializado pelas disputas em torno da definição dos legítimos beneficiários das cotas raciais.

O debate ocorrido por ocasião da audiência pública organizada pelo Senado em 2001 para discutir o Projeto de Lei n. 650, do senador José Sarney - propondo cotas para negros nos cargos públicos e nas universidades federais -, mostrou que, se o racismo havia se tornado ampla e institucionalmente reconhecido como característica constitutiva da sociedade brasileira, as ações afirmativas pareciam repousar sobre um terreno discursivo movediço no que diz respeito à definição de raça. Naquela ocasião, os legisladores se viram surpreendidos e intrigados com uma variedade de significados atribuídos à identidade negra, muitos deles conflitantes entre si.

O próprio conceito de afrodescendente parecia oscilar, naquele contexto, entre uma conotação biológica e outra político-cultural. Alguns argumentaram contra esse termo com base na ideia de que, a rigor, qualquer um no Brasil poderia se identificar como afrodescendente de acordo com pesquisas recentes a respeito da composição genética do povo brasileiro. Outros, ao contrário, asseveraram que o termo dizia respeito não a uma herança genética, mas cultural e era, portanto, legítimo na medida em que contemplava uma velha luta dos movimentos negros brasileiros, bem como a agenda antirracista das agências internacionais (Brasil, 2001).

Nesse sentido, as discussões em torno da adequação dos termos "afrodescendente" ou "negro", para fins de formulação de políticas públicas afirmativas, revelaram não só a ausência de um léxico racial oficial consolidado no Brasil, mas também uma suscetibilidade dos significados raciais - como, aliás, é próprio de todo e qualquer significado social - às disputas políticas historicamente condicionadas. Os casos de implementação de cotas da UERJ e da UnB

8. De fato, exceto a categorização por cor aplicada pelo IBGE na coleta do Censo e em alguns documentos, tais como certidão de nascimento ou certificado de reservista, as instituições brasileiras são conhecidas por terem se mantido, na maior parte das vezes, "cegas" no que diz respeito à classificação racial. 
demonstram, por exemplo, que a designação "afrodescendente" - até então louvada pelos movimentos negros com o intuito de livrar a identidade negra de sua conotação puramente biológica e pejorativa - tornou-se uma categoria por demais "ampla" do ponto de vista dos formuladores das políticas de cotas, inclusive para alguns ativistas negros. Essa designação, que, em outros contextos, havia sido evocada com o objetivo de chamar a atenção para a numerosa população negra no Brasil e, portanto, para a magnitude do problema do racismo neste país, passou a ser vista pelos projetos antirracistas afirmativos como brecha para fraudes. Embora isso tenha se tornado mais evidente na $\mathrm{UnB}$, onde a política de cotas repousou principalmente na "aparência negra", também no Rio militantes negros e defensores das cotas raciais demonstraram preocupação com o fato de que "brancos oportunistas" ou "brancos sociais" (pardos que poderiam se passar por brancos) se valessem do termo "afrodescendentes" para serem beneficiados. De fato, argumentos contrários às cotas raciais apoiaram-se na idéia de que a maioria dos brasileiros descende de africanos na tentativa de deslegitimar as políticas afirmativas. Desse modo, foi, realmente, com base nos termos pelos quais se deu a luta política naquele momento que os defensores das cotas salientaram as características físicas negras como principal aspecto constitutivo da identidade negra.

O termo "negro", por sua vez, foi considerado mais apropriado já que contemplava uma velha luta dos movimentos negros pela fusão dos termos "pardo" e "preto" numa só categoria "negro".

Aliás, no caso específico da UnB, onde o "fenótipo negro" foi institucionalizado como principal critério para identificar os beneficiários das cotas, a categoria "pardo" tornou-se particularmente controversa.

Cabe salientar, contudo, que, nesse contexto, a aparência física também ganhou preponderância (sobre outros aspectos definidores da identidade negra), com o objetivo específico de tornar a política viável, limitando o escopo dos potenciais beneficiários. Isso se confirma pelo depoimento de um dos membros da comissão designada pela UnB para regulamentar a política. De acordo com ele, tendo em vista as dificuldades práticas de incorporar todas as dimensões da identidade racial no processo de admissão, a universidade optou pela fotografia (Tavolaro, 2006, p. 176). Também, do ponto de vista de uma estudante, membro do Denegrir (Coletivo de Estudantes $\mathrm{Ne}-$ gros da UERJ), embora as características físicas não constituam o único aspecto definidor da identidade negra, ao tomá-la como critério, os formuladores de políticas públicas afirmativas poderiam inibir as fraudes (Tavolaro, 2006, p. 154).

É certo que o caráter circunstancial, instável e questionável dos significados raciais, conforme observado no contexto da implementação de cotas nas universidades públicas, não constitui prova da inexistência do racismo na sociedade brasileira e muito menos da inoperância da raça na vida social. Contudo, as disputas em torno de seus significados em contextos históricos, sociais e políticos específicos indicam que empregar a raça como "ponto de partida" (Lovemann, 1999) da pesquisa social pode ser equivocado, principalmente se o objetivo é precisamente o de compreender e explicar a raça como fenômeno social e seus modos de funcionamento na sociedade. Conforme Brubaker (2002), enquanto categoria de classificação socialmente construída que é - portanto, historicamente condicionada e suscetível ao modo de funcionamento das instituições e das lutas políticas -, a raça em si constitui um fenômeno que os sociólogos deveriam explicar e não um instrumento de explicação dos fenômenos sociais.

De certa forma, o debate em torno do caráter "real" da raça e sua validade enquanto conceito científico remete a alguns dos aspectos levantados por Bourdieu (1987) a respeito da existência teórica e prática das classes sociais. De acordo com esse sociólogo, a existência real das classes sociais é defendida por abordagens estruturalistas (ou objetivistas) que tendem a projetá-las como coletividades prontas na realidade social, independentemente das relações e processos que as tornam socialmente relevantes como princípio de "visão e de divisão do mundo". Nas palavras de Bourdieu (1987, p. 8):

[...] ao se assumir que as ações e interações poderiam de algum modo ser deduzidas da estrutura, negligencia-se a questão do movimento do grupo teórico para o grupo prático, ou seja, a questão da política e da operação política necessária, para que se imponha um princípio de visão e de divisão do mundo social, mesmo quando esse princípio é bem fundamentado na realidade.

Desse modo, aquilo que, de fato, resulta de uma operação analítica é automaticamente identificado na "realidade" como um "dado" que prescinde de maiores explicações. No entanto, a rejeição da existência real de classes sociais parece repousar numa perspectiva estritamente fenomenológica (ou subjetivista) que não identifica qualquer descontinuidade no "mundo real". Vistas sob esse prisma, as classes sociais são um mero construto científico sem qualquer fundamento na realidade social. Para Bourdieu, ambas as abordagens são equivocadas já que elas se baseiam numa visão "substancialista que não reconhece outra realidade senão aquela diretamente dada pela intuição da experiência ordinária” (p. 3).

As abordagens "substancialistas" da raça também derivam de perspectivas objetivistas e subjetivistas que ou afirmam ou negam seu status de "realidade" 
ao tomá-la como sinônimo de racismo. Em ambos os casos, o produto dos esquemas de percepção - sejam eles científicos ou senso comum - é tomado como sua causa. De fato, a refutação científica da raça e a falta de fronteiras raciais bem delineadas na "vida real" são normalmente apontadas como evidência da ausência do racismo no Brasil. Normalmente, esse tipo de abordagem considera raça apenas como fator biológico e não leva em conta a dinâmica histórica, política e social que a condiciona como significado social relevante.

Entretanto, a confusão teórica entre raça e racismo pode também resultar de análises que, ao contrário, salientam a persistência do racismo através de um enfoque exclusive em dados estatísticos que apontam para a distribuição desigual de bens, prestígio social e poder entre grupos raciais. Os grupos raciais tendem, nesse caso, a ser automaticamente projetados na realidade como coletividade que compartilha dos mesmos "interesses raciais" como se fossem "coisas" que já existiam antes dos esquemas de percepção. ${ }^{9}$ Apesar da importância de dados estatísticos a respeito da disparidade existente entre grupos racializados para diagnosticar as consequências do racismo nas sociedades contemporâneas, o uso da raça como premissa científica para explicar e compreender o racismo tem, no mais das vezes, resultado em análises que tendem a reproduzir a visão ordinária do mundo social. Ao partirem de grupos raciais, essas perspectivas de análise acabam por sugerir que o racismo é consequência e não a causa da divisão do mundo social em raças (Fields, 2003).

As análises "substancialistas" de raça são, contudo, também características de abordagens "subjetivistas" que justificam o seu uso como categoria analítica ao argumentarem que, se essa forma de categorização existe na cabeça das pessoas, ela também deve existir para o pesquisador. Ocorre que, conforme já salientado por Brubaker (2002), o problema de tomar as "categorias nativas" como categorias de análise científica sem levar e conta o processo através do qual elas se constituíram como significados sociais relevantes é que, ao fazê-lo, corre-se o risco de reproduzir as visões essencialistas do senso comum que identificam a "realidade" com aquilo que é imediatamente apresentado nas interações cotidianas e experiências sociais, como algo dado e pertencente à ordem natural das coisas. Desse modo, em vez de "analistas dos naturalizadores" nos tornamos "naturalizadores analíticos" (Brubaker, 2002, p. 166), ou em vez de analistas da raça, nos tornamos racistas analíticos.

Como contornar essa dificuldade epistemológica? Ou seja, como pode o cientista social investigar o fenômeno social da raça sem que ele sucumba aos ter- mos da ordem racista? É claro que esta é uma questão muito mais ampla que nos remete ao grande problema da objetividade nas ciências sociais. Penso, todavia, que, conforme já sugerido por Bourdieu (1990), ao nos comprometermos com uma análise permanentemente reflexiva a respeito de nosso próprio instrumental analítico ajudamos a solucionar parte do problema. Isso significa que uma sociologia crítica da raça deve, sim, estar atenta ao papel do cientista social na construção da realidade social. Sua perspectiva reflexiva com relação ao papel supostamente destacado do sociólogo não deve, contudo, se traduzir num pensamento ordinário do mundo social. Uma abordagem crítica e reflexiva é, portanto, aquela que se volta para os processos sociais, históricos, políticos específicos que tornam (ou não) a raça uma categoria de classificação social relevante e que se centra na sua dimensão relacional e situacional em vez de tomar seu caráter objetivo e coercitivo por certo.

\section{Considerações finais}

A digressão a respeito de três questões caras ao pensamento teórico social relativo à chamada questão racial - a relação entre classe e raça, a interface raça-cultura e, por fim, o status da raça como categoria social e conceito analítico - não é despropositada. Pelo contrário, conforme já explicitado no início deste artigo, constitui um esforço para elaborar um discurso teórico crítico da raça que cumpra com seu objetivo de interpretar e explicar o fenômeno da raça sem que se reproduza a respeito dela concepções de senso comum.

Contudo, a elaboração de um discurso teórico crítico da raça em um contexto marcado pela urgência da elaboração e implementação de políticas capazes de combater o racismo de forma eficaz e duradoura constitui uma tarefa das mais difíceis, já que implica também desconstruir, ao menos do ponto de vista analítico, aquele que constitui consequência e principal pilar de sustentação do racismo e das identidades raciais dentro da ordem racista, ou seja, a raça.

Qualquer experiência fenomenológica é capaz de atestar a força do racismo na sociedade brasileira contemporânea, experiência esta que se confirma a cada dado estatístico referente à enorme desvantagem dos negros no que tange à sua posição socioeconômica, bem como ao seu acesso à educação, saúde, emprego etc. Trata-se de uma ordem racista pautada na ideia de que as pessoas com uma determinada aparência, fenótipo, ou "herança genética", são naturalmente 
inferiores. Se esta é, contudo, uma ideia que não necessariamente é acionada de forma "consciente" por parte de um número considerável das pessoas, o que se dirá das instituições? $\mathrm{Na}$ verdade, a discriminação racial ocorre, no mais das vezes, com base na associação direta que o pensamento prático cotidiano estabelece entre negros e pobreza, negros e delinquência, negros e baixo nível de escolaridade, e assim por diante. Um fato que se deve à forma desproporcional e continuada com que esses fenômenos atingem a população negra deste país.

A ação afirmativa consiste precisamente em uma tentativa de remediar essa situação a médio prazo, de forma a garantir o acesso dos negros à universidade e, conseqüentemente, a sua ascensão socioeconômica e elevação de seu status social. Mas, como esta é uma medida antirracista destinada à promoção social de grupos racialmente categorizados, trata-se de uma política que não pode prescindir da raça e que, ademais, ao delinear seus beneficiários, também os categoriza e os classifica. Os formuladores de políticas públicas dessa natureza se veem, assim, diante de um grande desafio: como combater o racismo, a partir do interior da ordem racista, sem que se empregue a própria noção de raça?

Nesse sentido, a tarefa do pesquisador social, que opera de forma diretamente interconectada com a realidade social que pretende investigar, pode ser de grande valia, especialmente se esta se mantiver fiel aos propósitos de uma teoria crítica para a qual o questionamento do status quo implica fundamentalmente "pensar o pensamento", ou seja, refletir a respeito dos próprios métodos e conceitos tradicionais utilizados para interpretar a realidade social que ela ajuda a construir.

Pergunta-se, pois, que tipo de relação se estabelece entre raça e classe, ou entre raça e cultura, em circunstâncias históricas, políticas e em arranjos institucionais específicos, bem como se toma como objetivo principal de pesquisa explicar e entender os mecanismos através dos quais a raça se constitui em uma poderosa categoria de classificação social, em vez de analisar a sociedade a partir dela, ou com ela. Esses procedimentos são, desse modo, indispensáveis a uma teoria crítica da raça comprometida com a promoção da justiça social. 


\section{Referências}

AMERICAN SOCIOLOGICAL ASSOCIATION. The importance of collecting data and doing scientific research on race. Washington, DC: American Sociological Association, 2003.

AZEVEDO, Célia Maria Marinho de. O anti-racismo e seus paradoxos: reflexões sobre a cota racial, raça e racismo. São Paulo: Annablume, 2004.

BALIBAR, Etienne. Racism and politics in Europe today. New Left Review, n. 86, p. 5-19, 1991.

BALIBAR, Etienne; WALLERSTEIN, I. Race, nation, classe: les identities ambigues. Paris: Edition La Decouverte, 1990.

BONILLA-SILVA, Eduardo. Rethinking racism: toward a structural interpretation. American Sociological Review, n. 62, v. 3, p. 465-480, 1997.

BOURDIEU, Pierre. What makes a social class? On the theoretical and practical existence of groups. Berkeley Journal of Sociology, n. 32, p. 1-18, 1987.

BOURDIEU, Pierre. Objectification objectified. In: . The logic of practice. Stanford, CA: Stanford University Press, 1990. p. 30-41.

BRASIL, Senado Federal. Comissão de Cidadania e Justiça. Ata da audiência pública de 3 de outubro de 2001. Brasília, 2001.

BRUBAKER, Rogers. Ethnicity without groups. Archives Européennes de Sociologie, n. 43, v. 2, p. 163-189, 2002.

BURDICK, John. The lost constituency of Brazil's black movements. Latin American Perspectives, n. 25, v. 1, p. $136-$ 155, 1998.

CARVALHO, José Jorge; SEGATO, Rita Laura. Uma proposta de cotas para estudantes negros na Universidade de Brasília. Brasília: Departamento de Antropologia/ Universidade de Brasília, 2002. (Série Antropologia, n. 314).

CARVAlHO, José Jorge; SEGATO, Rita Laura. Plano de metas para a integração social, étnica e racial da UnB. Brasília: Departamento de Antropologia/Universidade de Brasília, 2004. Disponível em: <http://www.unb.br/portal/admissao/sistema_cotas/index.php\#apoio $>$. Acesso em: 12 jan. 2005

CORNELL, Stephen; HARTMANN, Douglas. Ethnicity and race: making identities in a changing world. Thousand Oaks, London, New Delhi: Pine Forge Press, 1998.

DURKHEIM, Émile. The rules of sociological method. New York: The Macmillan Press, 1982.

FEKETE, Liz; WEBBER, Frances. Inside racist Europe. Londres: Institute of Race Relations, 1994.

FIELDS, Barbara Jeanne. Of rogues and geldings. American Historical Review, n. 108, v. 5, p. 1397-1405, 2003.

FRY, Peter. A persistência da raça: ensaios antropológicos sobre Brasil e África Austral. Rio de Janeiro: Civilização Brasileira, 2005.
GILROY, Paul. Against race: imagining political culture against the color line. Cambridge, MA: The Belknap Press of Harvard University Press, 2001.

GUIMAR ÃES, Antônio Sérgio. Acesso de negros às universidades públicas. Cadernos de Pesquisa, n. 118, p. 247268, 2003.

HALL, Stuart. Introduction: Who needs identity?. In: HALL, Stuart; DU GAY, Paul (Ed.). Questions of cultural identity. London/Thousand Oaks/New Delhi: Sage Publications, 1996. p. 1-17.

HASENBALG, Carlos. Discriminação e desigualdades raciais no Brasil. Rio de Janeiro: Edições Graal, 1979.

JENKINS, Richard. Rethinking ethnicity: arguments and explorations. London/Thousand Oaks/New Delhi: Sage Publications, 2001.

LOVEMANN, Mara. Is 'race' essential?. American Sociological Review, n. 64, v. 6, p. 891-898, 1999.

MILES, Robert. Appropos the idea of 'race'... again. In: BACK, Les; SOLOMOS, John (Ed.). Theories of race and racism: a reader. London/New York: Routledge, 2000.

OMI, Michael; WINANT, Howard. Racial formation in the United States: from the 1960s to the 1990s. New York/ London: Routledge, 1994.

PINHO, Patrícia de Santana. Reinvenções da África na Bahia. São Paulo: Annablume, 2004.

PINTO, Paulo Gabriel Hilu da Rocha. Ação afirmativa, fronteiras raciais e identidades acadêmicas: uma etnografia das cotas para negros na Uerj. Paper delivered at the $1^{\text {a }}$ Conferência Internacional da Rede de Estudos de Ação Afirmativa. Rio de Janeiro: UCAM, 2004. Disponível em: $<$ http://aasn.iuperj.br/Articles Paulo-Gabriel-Hilu. pdf $>$. Acesso em: 3/4/2005.

RIO DE JANEIRO (Estado). Diário Oficial. Ordem do Dia, Rio de Janeiro, 13 ago. 2003, ano XXIX, n. 151, parte II, 2003.

STOLCKE, Verena. Cultura europeia: uma nova retórica de exclusão? Revista Brasileira de Ciências Sociais, n. 22, p. 20-31, 1993.

TAVOLARO, Lília Gonçalves Magalhães. Race and quotas, 'race' in quotes: the struggle over racial meanings in two Brazilian public universities. 2006. Tese (Ph.D. em Sociologia) - Departamento de Sociologia da New School for Social Research, Nova York, 2006.

WEBER, Max. Ensaios de sociologia. 5. ed. Rio de Janeiro: Guanabara Koogan, 1982.

WILSON, William Julius. The declining significance of race. Chicago/London: Chicago University Press, 1980.

WINANT, Howard. The theoretical status of the concept of race. In: BACK, Les; SOLOMOS, John (Ed.). Theories of race and racism: a reader. London/New York: Routledge, 2000 . 


\title{
Race, class and culture in the context of affirmative action: a theoretical critical effort on race
}

\begin{abstract}
This paper seeks to analyze three interrelated aspects of the theoretical discussions around "race relations" that were somehow recast in the context of the implementation of quotas for black people in Brazil, namely: 1) the relationship between race and class; 2) the interface between race and culture; 3) the status of race both as a social category and an analytical concept. This will be done in light of the discussions that preceded and were also intensified during the introduction of the first quota policies in Brazilian public universities. First, the paper inquires into the theoretical debate on the interdependence between class and race while pointing to the ways through which these two categories interrelate in the context of affirmative action for black people. Second, it proposes a critical analysis of the theoretical interface between race and culture in light of the disputes regarding the meanings of black identity in this context. Finally, the article analyzes the discussions around racial meanings by occasion of the implementation of affirmative action policies for black people in order to develop reflexive thinking on race as an analytical concept.
\end{abstract}

Key words: race, racism, social class, ethnicity, affirmative action.

\section{Raza, clase y cultura en el contexto de las políticas de acción afirmativa: un esfuerzo teórico crítico con respecto a la raza}

\section{Resumen}

El presente artículo propone, como tarea principal, discutir tres cuestiones importantes para el debate sociológico sobre las llamadas “cuestiones raciales". Éstas fueron, de alguna manera, retomadas en el contexto de implementación de las políticas de cuotas en Brasil, a saber: 1) la relación entre raza y clase; 2) la interfaz de la raza con la cultura/etnia; y 3) el status de la raza como categoría social y concepto analítico. Esta discusión será hecha a la luz del debate que antecedió y se intensificó por ocasión de la introducción de las primeras políticas de cuotas en las universidades públicas. Inicialmente, se hace una incursión alrededor del embate teórico relativo a la interdependencia de las categorías raza y clase, de modo a ejemplificar la manera por la cual esas dos categorías se relacionan en el contexto de experiencia de acciones afirmativas para negros. Enseguida, el artículo hace una reflexión crítica respecto a la interfaz teórica entre raza y cultura, a la luz de las disputas relativas a los significados de la identidad negra en este contexto. Finalmente, se analizan las discusiones alrededor de los significados raciales en el contexto de la implementación de políticas públicas afirmativas, con el objetivo de proponer un análisis reflexivo sobre la raza como concepto analítico.

Palabras clave: raza, racismo, clase social, etnicidad, acciones afirmativas.

Data de recebimento do artigo: 31/3/2009

Data de aprovação do artigo: 2/8/2010 